\title{
Diagnostic Value of Estimating the Ratio of Serum Free Triiodothyronine to Free Thyroxine in Differenti- ating Graves' Disease from Thyroiditis
}

\author{
Nesma A. Ibrahim ${ }^{*}$ and Ahmed M. Hamam² \\ ${ }^{1}$ Department of Internal Medicine, Faculty of Medicine, Ain Shams University, Cairo, Egypt, and ${ }^{2}$ Depart- \\ ment of Internal Medicine, Armed Forces College of Medicine (AFCM), Cairo, Egypt.
}

\begin{abstract}
Background: As the treatment approaches of Graves' disease (GD) and thyroiditis are different, the differential diagnosis is essential. Aim: To assess the diagnostic value of free triiodothyronine (FT3) to free thyroxine (FT4) ratio for differentiation between GD and destructive thyroiditis. Subjects and Methods: The present study was conducted on 100 newly diagnosed thyrotoxicosis patients; 61 with thyroiditis (group 1) and 39 with GD (group 2) and 20 healthy, age-matched subjects representing a control group (Group 3). All participants underwent medical history taking and clinical examination, serum levels of thyroid-stimulating hormone (TSH), FT3, and FT4 were measured, Technetium 99m thyroid Scan was done to all recruited patients. Results: The present results recorded significant increases in FT3, FT4, and decreases in TSH levels in Graves' disease group than in the thyroiditis group. There was a statistically significant difference between the study groups regarding $\mathrm{FT}_{3} / \mathrm{FT}_{4}$ ratio, which was lower in thyroiditis group than in Graves' disease group ( $0.21 \pm 0.03$ in group 1 vs $0.35 \pm 0.18$ in group $2, p$-value $<0.01)$, while there was no significant difference between thyroiditis group and the control group. The FT3/FT4 ratio showed a predictive value, with an area under the ROC curve (AUC) of $0.936(95 \% \mathrm{Cl}$, 0.876-0.995) for Graves' disease vs. thyroiditis $(p<0.001)$. Based on the cutoff value of this ratio of more than 0.269 offered a sensitivity of $89.7 \%$ and specificity of $91.8 \%$. Conclusion: The results of the present study demonstrated that free thyroid hormones and the FT3/FT4 ratio are useful to differentiate Graves' disease from destructive thyroiditis.
\end{abstract}

Keywords: Graves' disease, Thyroiditis, Free Thyroid Hormones, FT3/FT4 ratio

\section{Introduction}

Thyrotoxicosis is a hypermetabolic status characterized by excess of thyroid hormones serum levels. It may occur because of hyperthyroidism, the release of stored hormone or exogenous thyroid hormone intake. However, hyperthyroidism is characterized by elevated thyroid hormone levels because of its excess synthesis and secretion from the thyroid gland. The most common causes are Graves' disease (GD), toxic multinodular goiter, and 
autonomous toxic nodule(1,2). Some studies reported that hyperthyroidism prev-alence in iodine-sufficient areas ranges from $0.2 \%$ to $1.3 \%(3,4)$. Overt and subclinical forms accounted for $0.5 \%$ and $0.7 \%$, respectively ${ }^{(4)}$. The incidence rate was 51 cases per 100,000 per year(3). The clinical presentation of thyrotoxicosis can provide clues for diagnosis, but not the etiology. It is crucial to identify the etiology of thyrotoxicosis, since symptomatic treatment is required in thyroiditis but extensive medical therapy as well as occasional thyroid ablation is needed in cases of $G D(5)$. Apart from typical clinical presentation, radioactive iodine (RAI) uptake, serum levels of TSH receptor antibody (TRAb), and evaluation of thyroidal blood flow on ultrasonography are commonly used $^{(6)}$. Total $\mathrm{T} 3$ to total $\mathrm{T} 4$ ratio can also be useful in the assessment of the proper etiology of thyrotoxicosis when scintigraphy is contraindicated $^{(4)}$. Measurement of $\mathrm{FT}_{3}$ and FT4 instead of total form is commonly performed, since free forms are less affected by thyroid hormone binding protein (TBP), $\mathrm{FT}_{3} / \mathrm{FT}_{4}$ ratio has been advocated for the differential diagnosis of $G D$ and destructive thyroiditis ${ }^{(5)}$. Therefore, the present study evaluated the usefulness of $\mathrm{FT}_{3} / \mathrm{FT}_{4}$ ratio in predicting the etiology of thyrotoxicosis, and its role in differentiating patients with GD from patients with destructive thyroiditis, especially those with painless thyroiditis and subacute thyroiditis.

\section{Subjects and Methods}

\section{Patients}

This was a prospective descriptive study that was done on patients attending endocrine outpatient clinic in El-Maadi Armed Forced Hospital, with diagnosis of thyrotoxicosis at their first visit and in whom thyroid scintigraphy could be done, in the period from July 2018 to February 2020. The diagnosis of thyrotoxicosis was made on clinical grounds (including heat intolerance, increased appetite, increased sweating, weight loss, muscle weakness, fatigue, tremors, and diffusely enlarged thyroid gland) along with values of thyroid function test results. The Institutional Ethics Committee approval was taken, and all participants gave informed consent before participating in the study.

\section{Study design}

The present study was conducted on 100 newly diagnosed thyrotoxicosis patients; 61 with thyroiditis (Group 1) and 39 with GD (Group 2) and 20 healthy, age-matched subjects representing a control group (Group 3). Diagnosis of subacute thyroiditis and painless thyroiditis based on the clinical presentations and low uptake values of thyroid scintigraphy. Graves' disease was diagnosed by clinical presentations and high uptake values of thyroid scintigraphy. Patients taking drugs that affect thyroid function or those who have already started antithyroid medication, patients below 15 years of age, pregnant patients, patients with palpable nodules and patients with single or multiple nodules discovered in thyroid scintigraphy were excluded.

\section{Methods}

Serum levels of TSH, FT3 and FT4, were measured, using automated chemiluminescent immunoassays (Architect i2000SR; Abbott Laboratories, Chicago, IL, USA). The laboratory reference ranges were $(0.35-4.94 \mu \mathrm{IU} / \mathrm{mL}),(2.63-$ $5.70 \mathrm{pmol} / \mathrm{L})$ and (9.01-19.04pmol/L) respectively. Technetium 99m Thyroid Scan was done at radiology centre in ElMaadi Armed Forced Hospital. Intravenous administration of $5 \mathrm{mCi}$ dosage of 
Tc 99m- per technetate was done and static image of thyroid gland after 20 minutes in multiple projections was taken. Quantification of total uptake of tracer by the gland was taken as percentage uptake of right and left lobe thus giving total uptake. Normal reference of total percentage uptake range was $0.5 \%-4 \%$. Uptake values below $0.5 \%$ was diagnosed as thyroiditis and above $4 \%$ as GD.

\section{Statistical analysis}

Statistical evaluation was carried out by using SPSS program version 21.0 (SPSS Inc., Chicago, IL, USA). Numerical data were presented as mean \pm standard deviation (SD) and categorical data were presented as number and percentage of total. An ANOVA test was done to compare the three groups. Quantitative variables were compared in the two groups via post hoc test. Chi Square test $\left(\mathrm{X}^{2}\right)$ was used to compare two qualitative variables. ROC curve was used to determine best cutoff, sen sitivity, and specificity of $\mathrm{FT}_{3}$ / FT4 ratio in predicting Graves' disease. Results were evaluated in $95 \%$ confidence interval and $P$ value $<0.05$ was considered statistically significant.

\section{Results}

A total of 120 subjects were included, and divided into three groups; as regard patients with destructive thyroiditis (subacute thyroiditis and painless thyroiditis) representing group 1, included 61 patients, their mean age were $38.03 \pm 8.92 \mathrm{yrs}$, of them 17 (27.87\%) were males, and 44 (72.13\%) were females. Group 2 included 39 patients with Graves' disease their mean \pm SD of age were $40.31 \pm 11.71 \mathrm{yrs}$, of them 12 (30.77\%) were males, and 27 (69.23\%) were females. Group 3 included 20 healthy, euthyroid subjects representing a control group, their mean $\pm S D$ of age were $39.60 \pm 12.48 \mathrm{yrs}$, of them 7 (35\%) were males, and 13 (65\%) were females.

\begin{tabular}{|c|c|c|c|c|c|}
\hline \multicolumn{6}{|c|}{ Table 1: Comparison between the study groups } \\
\hline & $\begin{array}{c}\text { Group } 1 \\
\text { (thyroiditis) } \\
(\mathrm{n}=61)\end{array}$ & $\begin{array}{c}\text { Group } 2 \\
(G D) \\
(n=39)\end{array}$ & $\begin{array}{l}\text { Group } 3 \\
\text { (Control) } \\
(n=20)\end{array}$ & $\mathrm{X}^{2} / \mathrm{F}$ & $P$ value \\
\hline Male; n (\%) & $17(27.87 \%)$ & $12(30.77 \%)$ & $7(35 \%)$ & \multirow{2}{*}{$0.827^{*}$} & \multirow{2}{*}{$0.381 *$} \\
\hline Female; n (\%) & $44(72.13 \%)$ & $27(69.23 \%)$ & $13(65 \%)$ & & \\
\hline Age (Years) & $38.03 \pm 8.92$ & $40.31 \pm 11.71$ & $39.60 \pm 12.48$ & 0.591 & 0.555 \\
\hline $\mathrm{TSH}(\mu \mathrm{IU} / \mathrm{ml})$ & $0.007 \pm 0.02^{\mathrm{a}, \mathrm{b}}$ & $0.004 \pm 0.01^{c}$ & $1.85 \pm 0.74$ & 54.235 & $<0.01$ \\
\hline FT3 (pmol/L) & $5.52 \pm 0.61^{\mathrm{a}, \mathrm{b}}$ & $8.60 \pm 8.68^{c}$ & $2.53 \pm 1.31$ & 72.424 & $<0.01$ \\
\hline $\mathrm{FT} 4(\mathrm{pmol} / \mathrm{L})$ & $19.59 \pm 2.38^{\mathrm{a}, \mathrm{b}}$ & $24.31 \pm 21.99^{c}$ & $15.44 \pm 2.32$ & 36.384 & $<0.01$ \\
\hline FT3/FT4 ratio & $0.21 \pm 0.03^{\mathrm{a}}$ & $0.35 \pm 0.18^{c}$ & $0.19 \pm 0.09$ & 60.523 & $<0.01$ \\
\hline \multicolumn{6}{|c|}{$\begin{array}{l}\text { *= Chi Square test; a, b, c= significantly different at } \mathrm{p}<0.05 \text {, using post hoc test } \\
\text { a=group } 1 \text { vs. group 2; b= group } 1 \text { vs. group 3; c= group } 2 \text { vs. group } 3 \\
\text { TSH= thyroid stimulating hormone; FT3= free triiodothyronine; FT4=free thyroxine } \\
\text { Age, } \mathrm{TSH}_{3} \mathrm{FT}_{3}, \mathrm{FT}_{4} \text { and } \mathrm{FT}_{3} / \mathrm{FT}_{4} \text { ratio are presented in mean } \pm \text { standard deviation }\end{array}$} \\
\hline
\end{tabular}

There was no statistically significant difference between the study groups regarding age and gender (Table 1). Regarding thyroid function tests, FT3 and
FT4 levels were higher in Graves' disease group than in thyroiditis group, the difference was statistically significant; (FT3, 8.60 $8.68 \mathrm{pmol} / \mathrm{L}$ in group 
2 vs $5.52 \pm 0.61 \mathrm{pmol} / \mathrm{L}$ in group $1, p<0.01$ ) and (FT4, 24.31 $21.99 \mathrm{pmol} / \mathrm{L}$ in group 2 vs $19.59 \pm 2.38 \mathrm{pmol} / \mathrm{L}$ in group $1, p<$ 0.01). While TSH levels were lower in Graves' disease group than in thyroiditis group the difference was statistically non-significant $(0.004 \pm 0.01$ $\mu \mathrm{lU} / \mathrm{ml}$ in group $2 \mathrm{vs} .0 .007 \pm 0.02 \mu \mathrm{lU} / \mathrm{ml}$ in group $1, p=0.011$ ). $\mathrm{FT}_{3} / \mathrm{FT}_{4}$ ratio was lower in thyroiditis group than in Graves' disease group, the difference was statistically significant $(0.21 \pm 0.03$ in group 1 vs $0.35 \pm 0.18$ in group 2, $p<0.01$ ), while there was no significant difference between thyroiditis group and the control group (Table 1, Figure 1). The $\mathrm{FT}_{3} / \mathrm{FT}_{4}$ ratio showed a predictive value, with an area under the ROC curve (AUC) of $0.936(95 \% \mathrm{Cl}, 0.876$ 0.995) for Graves' disease vs. thyroiditis $(P<0.001)$. Based on the cutoff value of this ratio of more than 0.269 offered sensitivity of $89.7 \%$ and specificity of 91.8\% (Table 2, Figure 2).

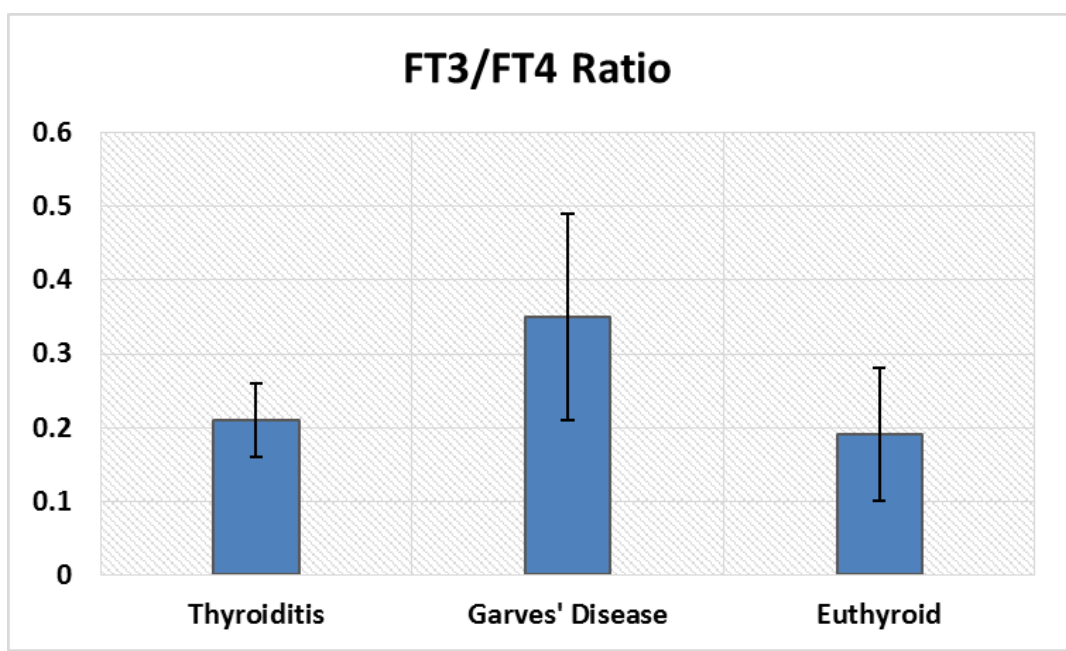

Figure 1: Comparison between the study groups regarding $\mathrm{FT}_{3} / \mathrm{FT}_{4}$ ratio. (High significant difference between the study groups)

\section{Discussion}

The initial assessment of thyrotoxicosis etiology is crucial to the appropriate clinical management. While the clinical diagnosis of patients is generally based on the physical examination and the laboratory results, it is difficult to differentiate $G D$ from painless thyroiditis based on the physical manifestations. Apart from the typical presentation of patients with thyrotoxicosis, RAI uptake, measurement of serum levels of TRAb, as well as thyroidal blood flow on ultrasonography are commonly used $^{(6)}$. Other markers that can assess the clinician in differentiating GD from subacute thyroiditis include; serum calcitonin levels(7), assessment of eosinophil to monocyte ratio ${ }^{(8)}$, stem cell factor $(9)$, total alkaline phosphatase activity(10), RBCs zinc concentration ${ }^{(11)}$, plasma fibrinogen levels ${ }^{(12)}$, and serial changes in liver function tests ${ }^{(13)}$. However, practically it is difficult to use such parameters. The use of ultrasonography for the differential diagnosis of thyrotoxicosis is less useful. However, when RAl uptake test is contraindicated (i.e. during pregnancy, lactation and in case of new iodine exposure), color flow Doppler ultrasonography may assist in diagnosing the etiology of thyrotoxicosis and to differentiate $G D$ from destructive thyroiditis ${ }^{(14)}$. RAI uptake test is a valuable method in 
differentiating the etiology of thyrotoxicosis; however, it is contradicted in some cases (i.e. during pregnancy and lactation). Moreover, exposure to large amounts of iodine prior to undergoing RAI uptake test may lead to RAI uptake suppression, resulting in an inappropriate diagnosis ${ }^{(6)}$.

\begin{tabular}{|c|c|c|c|c|c|}
\hline \multirow{2}{*}{$A \cup C$} & \multirow{2}{*}{ Cut-off } & \multirow{2}{*}{ Sensitivity } & \multirow{2}{*}{ Specificity } & \multicolumn{2}{|c|}{$95 \% \mathrm{Cl}$} \\
\hline & & & & Upper bound & Lower bound \\
\hline 0.936 & 0.269 & $89.7 \%$ & $91.8 \%$ & 0.876 & 0.995 \\
\hline
\end{tabular}

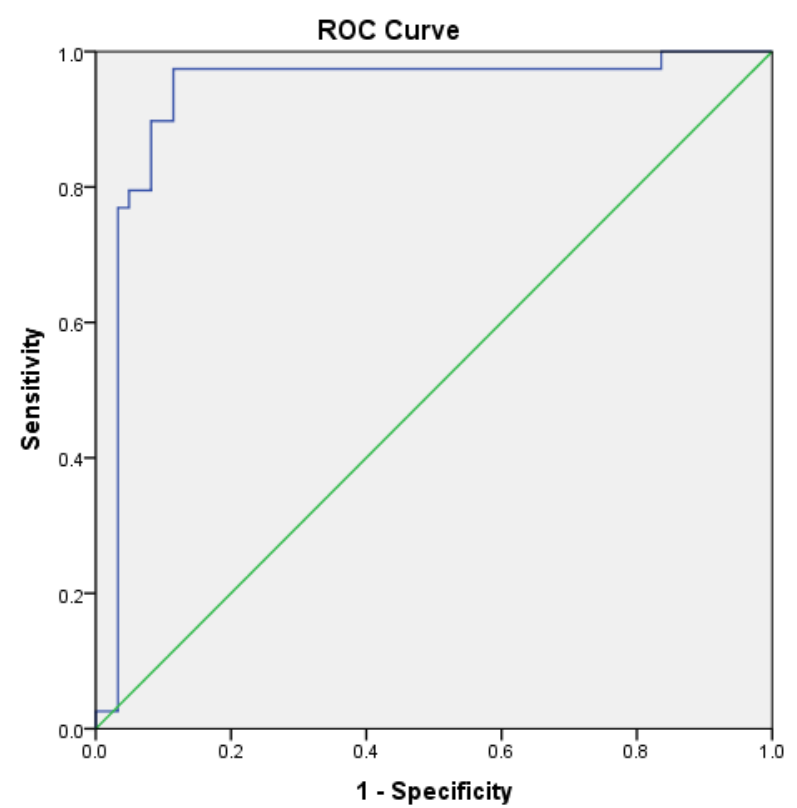

Figure 2: $\mathrm{ROC}$ curve to determine sensitivity and specificity of $\mathrm{FT}_{3} / \mathrm{FT}_{4}$ ratio in predicting Graves' disease

Measuring serum levels of TRAb has been commonly used in differentiating thyrotoxicosis etiology when RAI uptake is unavailable or contraindicated. However, patients with mild GD might have negative for $\operatorname{TRAb}^{(6)}$, TRAb may also be measured in patients with postpartum thyroiditis ${ }^{(15,16)}$. The ratio of total T3 to total T4 may also be useful in the assessment of thyrotoxicosis etiology when RAl uptake is contraindicated. The hyperactive gland produces more $\mathrm{T}_{3}$ than $\mathrm{T}_{4}$, resulting in elevation of $\mathrm{T} 3$ above the upper limit of normal more than $\mathrm{T} 4$ in thyrotoxicosis caused by hyperthyroidism, whereas $\mathrm{T} 4$ is elevated more than $\mathrm{T}_{3}$ in thyrotoxicosis caused by thyroiditis ${ }^{(17)}$. Shigemasa et al. revealed that the ratio of total $\mathrm{T}_{3}$ to total T4 (ng/lg) was >20 in GD and toxic nodular goiter, and $<20$ for painless or postpartum thyroiditis ${ }^{(18)}$. American Thyroid Association/American Association of Clinical Endocrinologists (ATA/AACE) guidelines recommend TRAb measurement and total T3/total T4 ratio as an alternative method for the diagnosis of GD in the absence of thyroid scintigraphy and uptake or when these are contraindicated ${ }^{(15)}$. 
However, TRAb measurement is not performed in many centers, it is expensive, and the results take time. Also, measurements of $\mathrm{FT}_{3}$ and $\mathrm{FT}_{4}$ are frequently ordered in the clinical practice ${ }^{(19)}$ rather than total $\mathrm{T}_{4}$ and $\mathrm{T}_{3}$ measurements, as the later are affected by serum TBG concentration which may be affected by many conditions in an unfavorable manner. So, a practical alternative was required for differentiating diagnosis in clinic. In the present study, we analyzed levels of $\mathrm{FT}_{3}, \mathrm{FT}_{4}$ and $\mathrm{FT}_{3} / \mathrm{FT}_{4}$ ratio in patients with GD and destructive thyroiditis (including subacute and painless thyroiditis). We found that the levels of FT3, $\mathrm{FT}_{4}$ and the $\mathrm{FT}_{3} / \mathrm{FT}_{4}$ ratio were higher in patients with GD than in those with thyroiditis. These results are consistent with the findings of previous literature. Yoshimura et al., reported that the $\mathrm{FT}_{3} / \mathrm{FT}_{4}$ ratio was useful in differentiating patients with GD and painless thyroiditis ${ }^{(5)}$. Moreover, Sriphrapradang et al. revealed that the $\mathrm{FT}_{3} / \mathrm{FT}_{4}$ ratio might help in differentiating the etiology of thyrotoxicosis, with a higher $\mathrm{FT}_{3} / \mathrm{FT}_{4}$ ratio suggesting GD, whereas a very low ratio supported the diagnosis of thyroiditis ${ }^{(20)}$. According to Izumi et al., the $\mathrm{FT}_{3} / \mathrm{FT}_{4}$ ratio was useful in differentiating $G D$ and destructive thyroiditis $^{(8)}$. However, Shigemasa et al. reported that the $\mathrm{FT}_{3} / \mathrm{FT}_{4}$ ratio was not useful in the differentiation between $G D$ and painless thyroiditis ${ }^{(18)}$. T3 is an active form of thyroid hormones that is resulted from the deiondinated $\mathrm{T} 4$ by type 1 iodothyronine deiodinase (D1) as well as type 2 (D2). In humans, it was found that the thyroid gland expresses both $\mathrm{D} 1$ and $\mathrm{D}_{2}{ }^{(21)}$. In Graves' thyroid tissue, there is a high expression of D2 which contribute to relatively high serum $\mathrm{T}_{3}$ levels $^{(22)}$. On the other hand, there is leakage of thyroid hormone from the breakdown thyroid follicle cell in destructive thyroiditis. In some cases of thyroiditis, the radioactive iodine uptake increases during the recovery phase and scintigraphy demonstrates increased activity leading to confusion with $G D^{(23)}$. So, patients in such phase were excluded from our study by asking their clinical history of interval decline in symptoms. According to our findings, $\mathrm{FT}_{3} / \mathrm{FT}_{4}$ ratio was useful in distinguishing the etiology of thyrotoxicosis. In the current era of economic crises, cost effectiveness is one of the most important health management concerns. Patients with mild GD or where thyroid scintigraphy were unavailable or contraindicated, the ratio of $\mathrm{FT}_{3} / \mathrm{FT}_{4}$ represents a simple and practical alternative to assess the cause of thyrotoxicosis. The finding of the present study is very helpful for both of patients and clinicians, in the settings of poor patient's compliance and limited country resources. However, $\mathrm{FT}_{3} / \mathrm{FT}_{4}$ ratio should be validated in other populations, and, due to the limited number of patients in our study, there is a need for studies with more patients. Selection of the recruited patients from a single center is another limitation of this study. Also, this ratio should not be applied to hospitalized patients who have the possibility of low T3 levels from nonthyroidal illness.

\section{Conclusion}

$\mathrm{FT}_{3} / \mathrm{FT}_{4}$ ratio is useful for differentiating GD from destructive thyroiditis, with lower cost and hazards than thyroid scintigraphy. So, in the absence of thyroid scintigraphy and uptake or when these are contraindicated, the $\mathrm{FT}_{3} / \mathrm{FT}_{4}$ ratio may be used as an alternative method for distinguishing the etiology of thyrotoxicosis. 
Acknowledgement: We wish to express our gratitude to the department of radiology and medical laboratory department, El-Maadi Armed Forced Hospital, for being helpful and offering invaluable guidance, support and assistance.

Funding: None

Conflicts of Interest: None

\section{References}

1. Devereaux D, Tewelde SZ. Hyperthyroidism and thyrotoxicosis. Emerg Med Clin N Am., 2014 (32):277-292.

2. Franklyn JA, Boelaert K. Thyrotoxicosis. Lancet 2012 (379):1155-1166.

3. Garmendia Madariaga A, Santos Palacios S, Guillen-Grima, F, Galofre J $C$. The incidence and prevalence of thyroid dysfunction in Europe: a meta analysis. J. Clin. Endocrinol. Metab. 2014 (99): 923-931.

4. Hollowell J G, Staehling NW, Flanders WD, Hannon WH, Gunter EW, Spencer CA, Braverman LE. Serum $\mathrm{TSH}, \mathrm{T}$ (4), and thyroid antibodies in the United States population (1988 to 1994): National Health and Nutrition Examination Survey (NHANES III). J. Clin. Endocrinol. Metab. 2002 (87) 489-499.

5. Yoshimura N J, Momotani N, Fukada S, Ito K, Miyauchi A, Amino N. Ratio of serum free triiodothyronine to free thyroxine in Graves' hyperthyroidism and thyrotoxicosis caused by painless thyroiditis. Endocr. J. 2005; 52 (5): 537-542.

6. Ross D S, Burch H B, Cooper D S, Greenlee MC, Laurberg P, Maia A L, Rivkees SA, Samuels $M$, Sosa J A, Stan M N, Walte M A. "2016 American Thyroid Association guidelines for diagnosis and management of hyperthyroidism and other causes of thyrotoxicosis," Thyroid 2016; 26 (10):1343-1421.
7. Amino N, Yabu Y, Miki T, Morimoto S, Kumahara $\mathrm{Y}$, Mori $\mathrm{H}$, Iwatani $\mathrm{Y}$, Nishi K, Nakatani K, Miyai K. Serum ratio of triiodothyronine to thyroxine, and thyroxine-binding globulin and calcitonin concentrations in Graves' disease and destruction-induced thyrotoxicosis. J. Clin. Endocrinol. Metab. 1981; 53 (1) 113-116.

8. Izumi Y, Hidaka Y, Tada H, Takano T, Kashiwai T, Tatsumi KI, Ichihara K, Amino N. Simple and practical parameters for differentiation between destruction-induced thyrotoxicosis and Graves' thyrotoxicosis. Clin. Endocrinol. 2002; 57(1):5158.

9. Yamada T, Sato A, Aizawa T, Ootsuka H, Miyahara $Y$, Sakai H, Terao A, Onuma $S$, Ito $\mathrm{Y}$, Kanamori A, Nakamura Y, Tejima E. An elevation of stem cell factor in patients with hyperthyroid Graves' disease, Thyroid 1998; 8 (6) 499-504.

10. Yanagisawa $T$, Sato $K$, Kato $Y$, Shimizu S, Takano K. Rapid differential diagnosis of Graves' disease and painless thyroiditis using total $\mathrm{T}_{3} / \mathrm{T}_{4}$ ratio, $\mathrm{TSH}$, and total alkaline phosphatase activity. Endocr. J. 2005; 52 (1) 29-36.

11. Sayama N, Yoshida K, Mori K, Fukazawa H, Hori H, Nakazato N, Tani J, Nakagawa $\mathrm{Y}$, Ito $\mathrm{S}$. Measurement of red blood cell zinc concentration with Zn-test kit: discrimination between hyperthyroid Graves' disease and transient thyrotoxicosis. Endocr. J. 1998; 45 (6): 767-772.

12. Ma J, Liu R, Wu D, Miao W, Chen Q, Li Y, Guan H. Utility of plasma fibrinogen in the differential diagnosis of thyrotoxicosis. Int. J. Clin. Exp. Med. 2015; 8 (1) 1220-1226.

13. Kubota S, Amino N, Matsumoto $\mathrm{Y}$, Ikeda N, Morita S, Kudo T, Ohye H, Nishihara E, Ito M, Fukata S, Miyauchi A. Serial changes in liver function tests in patients with thyrotoxicosis induced by Graves' disease and 
painless thyroiditis. Thyroid 2008; 18 (3) 283-287.

14. Bogazzi F, Vitti P. Could improved ultrasound and power Doppler replace thyroidal radioiodine uptake to assess thyroid disease? Nat Clin Pract Endocrinol Metab 2008; 4:7071.

15. Bahn Chair RS, Burch HB, Cooper DS, Garber JR, Greenlee MC, Klein I, Laurberg P, McDougall I R, Montori V M, Rivkees S A, Ross D S, Sosa J A, Stan M N. American Thyroid Association; American Association of Clinical Endocrinologists. Hyperthyroidism and other causes of thyrotoxicosis: management guidelines of the American Thyroid Association and American Association of Clinical Endocrinologists. Thyroid 2011(21): 593-646.

16. Gorman CA. Radioiodine and pregnancy. Thyroid 1999 (9):721- 726.

17. Carle A, Knudsen N, Pedersen IB, Perrild $H$, Ovesen L, Rasmussen LB, Laurberg P. Determinants of serum $\mathrm{T}_{4}$ and $\mathrm{T} 3$ at the time of diagnosis in nosological types of thyrotoxicosis: a population-based study. Eur J Endocrinol 2013(169):537-545.

18. Shigemasa C, Abe K, Taniguchi $S$, Mitani Y, Ueda Y, Adachi T, Urabe K, Tanaka T, Yoshida A, Mashiba H. Lower serum free thyroxine ( $\mathrm{T}_{4}$ ) levels in painless thyroiditis compared with Graves' disease despite similar serum total T4 levels. J Clin Endocrinol Metab 1987(65): 359363.

19. Thienpont $L M$, Van Uytfanghe $K$, Poppe K, Velkeniers B. Determination of free thyroid hormones. Best. Pract. Res. Clin. Endocrinol. Metab. 2013; 27 (5) 689-700.

20. Sriphrapradang C, Bhasipol A. Differentiating Graves' disease from subacute thyroiditis using ratio of serum free triiodothyronine to free thyroxine. Ann Med Surg (Lond) 2016; (10): 69-72.
21. Bianco A C, Salvatore D, Gereben B, Berry M J, Larsen P R. Biochemistry, cellular and molecular biology, and physiological roles of the iodothyronine selenodeiodinases. Endocr. Rev. 2002; 23 (1) 38-89.

22. Salvatore $D, T u ~ H$, Harney J W, Larsen P R. Type 2 iodothyronine deiodinase is highly expressed in human thyroid. J. Clin. Invest. 1996; 98 (4) $962-968$.

23. Smith JR, Oates E. Radionuclide imaging of the thyroid gland: patterns, pearls, and pitfalls. Clin Nucl Med. 2004;29(3):181-93. 